\title{
The effect of a low-carbohydrate diet on biomarkers of bone health in pre- and post-menopausal females: a randomized control crossover trial
}

\author{
D. Fitzmaurice and L. Doyle \\ Department of Health, Sport and Exercise Science, School of Health Sciences, Waterford Institute of Technology, \\ Republic of Ireland
}

In an Australian study of 1200 subjects $17 \%$ had tried or intended to try a low-carbohydrate diet, and $70 \%$ believed they should cut back on carbohydrates to lose weight ${ }^{(1)}$. With increasing levels of obesity, the low-carbohydrate diet has become popular as a weight loss method. While weight loss through consumption of a low carbohydrate diet has been proven ${ }^{(2)}$ there is contradictory evidence regarding its effect on bone health ${ }^{(3,4)}$. Furthermore the effect of this diet on bone health for greater than 12 weeks is unknown. The aim of this study was to assess the effect of a low-carbohydrate diet consumed over 24 weeks on biomarkers of bone health in pre- and postmenopausal females.

Following ethical approval and informed consent subjects were screened. 24 females (13 pre-menopausal; 11 postmenopausal) were randomly assigned to a control $(\mathrm{AB})$ or low-carbohydrate diet (BA) group for 24 weeks. Subjects were then crossed over to the alternative dietary regimen for 24 weeks. Blood and urine samples taken at week 24 and 48 were analysed for biomarkers of bone resorption and formation using ELIZA. Urine $\mathrm{pH}$ was measured and a 3 day food diary analysed using CompEat ${ }^{(\mathrm{m}}$. Data was analysed for treatment and carryover effects using unpaired t-tests. Non-parametric tests were used where data was not normally distributed.

Table 1. Dietary and bone biomarker differences between groups at end of control and dietary periods

\begin{tabular}{|c|c|c|c|c|c|}
\hline \multirow[b]{2}{*}{ Parameter } & \multicolumn{2}{|c|}{ Control } & \multicolumn{2}{|c|}{ Low-carbohydrate } & \multirow[b]{2}{*}{ Treatment $P$ value } \\
\hline & Mean & SD & Mean & SD & \\
\hline Carbohydrate (g/d) & 179.26 & 51.98 & 91.38 & 37.56 & 0.000 \\
\hline Protein $(\mathrm{g} / \mathrm{d}) /$ Carbohydrate $(\mathrm{g} / \mathrm{d})$ & 0.42 & 0.11 & 0.98 & 0.53 & 0.000 \\
\hline Calcium (mg/d) & 747.28 & 299.05 & 663.30 & 279.01 & 0.132 \\
\hline Urine $\mathrm{pH}$ & 5.76 & 0.40 & 5.81 & 0.48 & 0.691 \\
\hline Serum osteocalcin $(\mathrm{ng} / \mathrm{ml})$ & 13.83 & 6.67 & 12.95 & 5.05 & 0.228 \\
\hline Serum CTx $(\mathrm{ng} / \mathrm{ml})$ & 0.34 & 0.20 & 0.35 & 0.22 & 0.837 \\
\hline Serum BALP (ug/L) & 13.71 & 5.36 & 12.83 & 4.39 & 0.357 \\
\hline Urine NTx (nmol BCE/mMol Creatinine)* & 30.75 & 12.59 & 37.27 & 16.71 & 0.081 \\
\hline
\end{tabular}

* Presence of carryover effects, data from AB group only, was analysed.

Although carbohydrate intake and protein/carbohydrate ratio significantly $(P<0.05)$ changed between control and dietary periods, there was no evidence of an effect on calcium intake, urine $\mathrm{pH}$ or biomarkers of bone formation (serum osteocalcin and BALP) and resorption (serum CTx and urinary NTx).

This work was supported by Strand III funding under the Technological Sector Research grant.

1. Crowe T \& Cameron-Smith D (2005) Med J Australia 182, 594-595.

2. Gardner C, Kiazand A, Alhassan S et al. (2007) JAMA 298, 178.

3. Carter J, Vasey F \& Valeriano (2006) Osteoporosis Int 17, 1398-1403.

4. Reddy S, Wanh C, Sakhaee K et al. (2002) J Kidney Dis 40, 265-274. 